\title{
Minimally invasive diagnosis of endometriosis
}

\author{
Catalina Diana STANICA, Adrian NEACSU, Romina Marina SIMA, Raluca Gabriela IOAN \\ Department of Obstetrics and Gynecology, "Carol Davila" University of Medicine and Pharmacy, Bucharest
}

\begin{abstract}
Endometriosis is a common condition among women of reproductive age that can cause chronic pelvic pain and infertility. Rapid establishment of a positive diagnosis of endometriosis is essential for effective management.

The positive diagnosis of endometriosis is difficult to establish and requires invasive methods. The "golden standard" for diagnosis is still laparoscopy. Current research has not yet established specific non-invasive diagnostic methods for endometriosis. Imaging techniques, endometrial or serum markers facilitate diagnosis and are useful in monitoring the patient's progress.

A number of noninvasive investigations, such as imaging techniques, or biomarkers are currently being evaluated for use in routine practice. A combination of these noninvasive tests could be the standard for diagnosing endometriosis in the future.
\end{abstract}

Keywords: endometriosis, noninvasive diagnosis, imaging diagnosis

\section{INTRODUCTION}

Endometriosis is a common gynecological condition, found in women of reproductive age, with important implications for their quality of life and married life. The costs involved in the diagnosis and treatment of endometriosis, not negligible, have special socio-economic consequences.

The exact pathophysiological mechanisms involved in the onset and progression of the disease are not known. Endometriosis can be classified as adenomyosis (endometriosis developed in the thickness of the myometrium) and endometriosis itself (development of ectopic endometrial tissue outside the uterus), with genital or extragenital location, can affect the large intestine at different levels, appendix, urinary tract, respiratory tract brain, skin etc.

In the case of a woman of childbearing age who has chronic pelvic pain (dysmenorrhea, dyspareunia, inter- menstrual pain), infertility, dysuria, rectal tenesmus, hematuria, hemoptysis, the diagnosis of endometriosis should be considered. The symptoms have a cyclical character, similar to the menstrual cycle (1).

The positive diagnosis of endometriosis involves the use of invasive methods that allow the visualization of lesions and the taking of tissue samples from suspicious lesions. The anatomo-pathological examination of the samples taken establishes the diagnosis of certainty. This is currently the "gold standard" in the diagnosis of endometriosis (2). There is currently no minimally invasive paraclinical test to establish a definite diagnosis of endomertiosis. Currently available investigations supplement only clinical data, strengthening the suspicion of the diagnosis of endometriosis and also allowing monitoring of treatment.

About $10 \%$ of women of reproductive age suffer from endometriosis, and recent epidemiological data show an increase in the incidence of the disease (3). 
The condition affects a woman's quality of life and reproductive potential, by decreasing fertility. The discovery of non-invasive diagnostic tests, of population screening methods, which would allow the start of treatment from an early stage, would therefore be very useful.

The development of imaging methods, the extraordinary advances registered in the field of genetics, of the study of biological, cellular and molecular markers, constitute premises for the discovery of new efficient methods of diagnosis and treatment in endometriosis.

\section{OBJECTIVE AND METHOD}

The objective of this paper was to identify in the literature new minimally invasive methods for diagnosing endometriosis.

We searched in electronic databases (PubMed, Google Scholar) articles and clinical studies published in recent years, which identify minimally invasive methods for diagnosing endometriosis. We selected only the materials that specify that they went through the peer review procedure.

\section{BIOMARKERS USED TO DETECT ENDOMETRIOSIS}

The definite diagnosis of endometriosis still involves invasive techniques (laparoscopy and laparotomy). Current research seeks to establish non-invasive, reliable, relatively low-cost methods for diagnosing endometriosis.

Understanding the pathophysiological mechanisms involved in the onset and progression of endometriosis has led to the study of a large number of possible biological, cellular or molecular markers that could have practical utility in the diagnosis of endomertiosis $(4,5)$. Hormonal, immunological mechanisms are studied, which involve adhesion molecules and cellular receptors, as well as biochemical changes in the eutopic or ectopic endometrium. Many of the studies have had promising results in animal or in vitro models, not in human patient studies, but research is ongoing.

In recent years, a number of serological markers, peritoneal fluid, or menstrual flow have been studied (6-9).

The most widely used serological marker today is the CA-125 antigen. This is a high molecular weight surface glycoprotein (20 Kilodaltons), whose serum concentration increases in women with endometriosis, correlated with the stage of the disease. The marker is useful in monitoring treatment (values decrease after administration of danazol or GnRh agonists), or in monitoring the recurrence of post-therapeutic disease
$(10,11)$. However, its sensitivity and specificity are low, with elevated plasma levels being found in other conditions (epithelial neoplasms, pericarditis, pancreatitis etc.).

Serological markers such as the antigens CA-72, CA 15-3, CA 19-9, TAG-72 have not yet demonstrated their utility in the diagnosis of endometriosis (12-14). In the case of placental protein 14 (PP14) there is a very good correlation with the stage of the disease $(15,16)$. Also, the specificity for diagnosing endometriosis when determining antiendometrial antibodies can reach almost $100 \%(17,18)$.

In endometriosis, cytokines $(19,20)$ appear to have a profound effect on the implantation of endometriotic sources by reducing immunological surveillance and identifying and destroying endometrial cells. Of these, IL- 6 has been the most studied in recent decades, with good sensitivity and specificity. However, it is better that future studies focus on the diagnostic efficacy of IL-6 combined with other cytokines.

In an attempt to pinpoint the existence and location of endometriotic implants as accurately and less invasively as possible, the use as markers of substances that specifically combine with surface receptors of ectopic endometrial tissue is tested. Laser-induced luminescence is based on the fact that a tissue, exposed to light of a certain wavelength, emits fluorescence in a specific spectrum, as well as some tissue-specific drugs. It was found that tamoxifen has the best concentration in endometriotic implants, its highlighting can be done with an argon-ion laser (21). A similar method is based on the use of 5-aminolevulinic acid that accumulates in endometriotic tissue, where it is converted to protoporphyrin IX, which has the ability to emit fluorescent (22).

There are studies of monoclonal antibodies that bind specifically to target endometriotic cells that facilitate the definite diagnosis of endometriosis, but also open up new therapeutic options for the use of cytotoxic substances or inhibitors of ectopic endometrial activity related to these "carrier" (23).

Studies have found that miRNAs obtained from diseased tissues and other body fluids have been able to detect various diseases (24). MiRNA deregulation is involved in the pathophysiology of endometriosis and has been investigated as potential biomarkers, however additional validations in a large population using a standardized reproducible methodology to further clarify the diagnostic potential of miRNAs.

There are studies on the altered expression of certain genes in endometriotic implants, or protein subsets secreted by ectopic endometrial tissue (25-27). Out of a total number of 4,133 genes studied, 8 genes were identified as altered in endometriotic tissue. 


\section{IMAGING METHODS FOR DIAGNOSING ENDOMETRIOSIS}

The two-dimensional transvaginal ultrasound examination proved to be very useful in detecting ovarian endometriomas with a diameter greater than $10 \mathrm{~mm}$, but also in differentiating them from other adnexal masses, as well as in following their evolution under drug treatment.

The cystic character with homogeneous hypoechoic appearance, with the presence of echoes of low intensity, are considered the basic ultrasound characteristics of ovarian endometriomas (28-30). In addition, other elements were identified that increased the specificity and sensitivity of the method: cystic wall thickness, multilocularity, the presence of parietal hyperechoic nodules (31-33). The differential diagnosis of ovarian endometrioma is made with other ultrasound-like adnexal masses: hemorrhagic cyst, functional luteal cyst, dermoid cyst, neoplasms. As suggestive ultrasound elements for neoplasms we mention high wall thickness, irregularity, inhomogeneity, the presence of septa or vegetation etc.

The use of Doppler ultrasound (color Doppler, pulsed Doppler, Power Doppler) can increase the accuracy of the diagnosis, allowing the study of parietal vascularization, more developed in the case of malignant formations (34-36).

Transvaginal ultrasound can visualize endometriotic nodules (solid hyperechoic lesions) from $0.5 \mathrm{~cm}$ in size, located at the level of the recto-vaginal septum, the bottom of the Douglas sac, or the anterior rectal wall. The sensitivity of detection, in the case of deep involvement of the rectal wall, is higher for echoendoscopy, or transrectal ultrasound (37). $7.5 \mathrm{MHz}$ or $10 \mathrm{MHz}$ probes are used which ensure a better resolution, increasing the sensitivity of the ultrasonographic investigation. The examination is more painful if it occurs during menstruation. Bladder lesions can be visualized by ultrasound in the form of hyperechoic nodules with reduced vascularization, most commonly located in the posterior bladder wall (38). Ultrasound also allows minimally invasive investigations, avoiding unnecessary surgery. Thus, biopsy puncture can be performed under ultrasound guidance, of the ovarian endometrioma, or its aspiration, a useful procedure in case of differential diagnosis, or monitoring the evolution, in case of recurrence of cystic formation (39). The sensitivity and specificity of ultrasonography is very low in the detection of superficial ovarian or peritoneal endometriotic implants.

Therefore, new techniques with contrast substance, harmonic Power Doppler, tissue Doppler and even three-dimensional reconstruction of pelvic structures have emerged, useful especially in the case of adhesions (40).
Another useful investigation in the positive diagnosis of endomeriosis is sonohisterography. This was proposed for further study of salpinges (41), being a combination of transvaginal ultrasound and instillation into the uterine cavity of a saline or opaque solution following the passage of its tubal passage and the appearance of fluid in the bottom of the Douglas sac. Sonohisterography is useful in differentiating endometriosis adenomyosis and in investigating tubal infertility, being an alternative to hysterosalpingography.

Ultrasound remains the initial choice in the assessment of adnexal masses, but nuclear magnetic resonance (NMR), also a non-invasive method, can be much more useful, with better sensitivity and specificity (in the case of peritoneal implants or adhesions), with the possibility of perform sections on several planes and with good reproducibility. However, it is a more expensive investigation technique with less accessibility. Identification of endometriosis by MRI is based on the detection of chronic bleeding in suspicious lesions. The presence of degraded blood in the endometriotic ovarian cyst appears as a homogeneous image, hyperintense in T1 and hypointense, with small hyperintense areas in T2. In case of recent bleeding, the signal is hyperintense in both $\mathrm{T} 1$ and $\mathrm{T} 2$. Peritoneal lesions appear as nodules, with hyperintense signal in $\mathrm{T} 1$ and $\mathrm{T} 2$, and adhesions can be identified by changing the position of the organs involved (42-46). Deep lesions in the rectovaginal septum may have a signal similar to the myometrial one in T1, with small areas of signal intensification indicating the presence of microendometriomas. In some cases there is a transition zone adjacent to the node, an area with a hyperintense signal, called the "safety zone", probably represented by interposed adipose tissue, especially anterior to the rectum $(47,48)$. The use of the so-called lipid subtraction technique (inhibition of the lipid signal) can facilitate the differential diagnosis of ovarian endometriomas with dermoid cysts. The sensitivity and specificity of the method can be increased by administering a contrast agent (gadolinium) (49).

High-resolution devices are currently used, as well as three-dimensional reconstruction programs, which ensure a better view of the pelvic structures and a more correct interpretation of the relationships between the organs, useful in the case of adhesions. MRI examination also allows therapeutic monitoring, especially in the case of ovarian endometriosis (50).

Interest in radiological investigations in the diagnosis of endometriosis has declined recently due to irradiation, poor sensitivity and specificity, as well as due to the existence of other methods that provide more accurate information about the number and location of lesions. Hysterography/hysterosalpingography has lost ground to sonohysterography or MRI, being used only 
in centers where no other methods are available to highlight indirect signs of pelvic endometriosis, to differentiate adenomyosis and to investigate tubal permeability. Barium esophagus-gastro-duodenal transit, or irigography, may be useful in some situations of damage to the digestive tract. IV urography or retrograde pyelography may reveal endometriotic lesions at the ureteral or bladder level, possibly deviation or obstruction due to the involvement of the ureter in severe adhesion processes $(51,52)$. Chest radiological examination may be useful in the presence of pleuropulmonary endometriotic implants (53).

Computed tomography (CT) is superior to radiological examination, but inferior to MRI in terms of sensitivity and specificity, and it may provide useful information in the thoracic, abdominal, cerebral, or pelvic locations of endometriotic lesions (54).

\section{MINIMALLY INVASIVE METHODS OF DIAGNOSING ENDOMETRIOSIS}

Methods of direct visualization of endometriotic lesions include: hysteroscopy, salpingoscopy (falloposcopy), colposcopy, rectosigmoidoscopy, colonoscopy, cystoscopy.

Direct visualization of the interior of the uterine cavity and the tubal lumen is used not only in the diagnosis of endometriosis, but also of other diseases: submucosa fibroids, endometrial carcinoma, polyps, infertility. Salpingoscopy can investigate the tubal lumen from its uterine ostium to the level of the fimbriae. It can thus highlight the existence of tubal obstructions, intraluminal adhesions, endotubic polyps, hydrosalpinx or intraluminal endometriotic lesions (55). The minimization of the instrumentation and the possibility of using prostaglandins to dilate the cervix, have facilitated the application of this technique even on an outpatient basis, with minimal discomfort for the patient.

Colposcopy identifies endometriotic lesions with high cervical or vaginal localization (56).

Rectosigmoidoscopy and colonoscopy are used in case of suspicion of endometriotic foci located in the wall of the lower digestive tract, with varying degrees of penetration. Submucosal lesions, however, can cause bleeding, visible especially if the examination is performed during menstruation. They appear as mucosal folds, usually pigmented. These examinations allow the collection of tissue material from the suspicious areas, necessary for the histopathological examination. The biopsy can also be guided by echoendoscopy, which provides great accuracy (57).

Cystoscopy is an investigation that addresses patients with urinary symptoms. In the case of bladder endometriosis, the appearance of endometriosis is that of congestive edematous mucosa, which may be intact or with erosions. Blue-blackish or reddish-brown areas often appear. If the location of the implant is in the thickness of the bladder wall, towards the superficial tunics, the appearance of the mucosa is quasi-normal, or has a small prominence on the surface. The lesions are often $1-4 \mathrm{~cm}$ in size and are located in the posterior wall or in the bladder trine. Examination allows biopsy of suspicious lesions necessary for histopathological examination (58).

Laparoscopy is still the "gold standard" in the positive diagnosis of endometriosis. Laparoscopy requires cold light, a double-pointed technique, and instrumentation for biopsies. The recent introduction of miniaturized instruments (less than $5 \mathrm{~mm}$ ) allows the procedure to be performed even on an outpatient basis. Sometimes extended adhesions prevent visualization and characterization of lesions, or biopsies. In this case a subsequent laparotomy is indicated. On laparoscopic examination, the lesions appear as small spots on the peritoneum, about $2 \mathrm{~mm}$ in size, blue, purple or dark brown-brown, which can be seen on the surface of the ovary that looks "burned by gunpowder" in the ovarian fossae, uterine sacrates ligaments, uterus, fallopian tubes and peritoneum of the bladder and recto-uterine sac bottoms (59).

The 1985 American Fertility and Sterility Society classification (60) took into account these "typical" lesions for the 4 stages of endometriosis: minimal, mild, moderate, or severe. Subsequent studies (61) have shown that other lesions are considered to be atypical (small, white, opaque peritoneal areas; areas with subovarian adhesions, circular peritoneal defects with the surrounding surface pleated and retracted; bright red spots, ecchymotic, surrounded by a congestive area vesicles of different colors) are positive for endometriosis on histopathological examination in a proportion of more than $81 \%$. As a result, the revised Classification of the World Endometriosis Society also took into account these types of lesions to establish the lesion score (62).

Another relatively recently introduced technique is hydrolaparoscopy, in which the video camera is inserted through the bottom of the posterior vaginal sac, after instilling a saline solution into the bottom of the Douglas sac (63).

Contact peritoneoscopy uses an image magnification system (20x-40x) that allows a more detailed analysis of the appearance of the lesion and the assessment of its vascularity. In a study of 140 patients, the authors described the existence of two major types of lesions, active and less active, depending on the appearance of the perilesional vessels, the degree of impregnation with hemosiderin and the presence of fibrous, scarring tissue (64).

Another recent use of laparoscopy in the diagnosis of endometriosis is the construction of maps of painful 
areas by touching the lesion areas and perilesional areas, the patient being only slightly sedated, conscious. It has been shown that there are painless lesions, but also areas with a normal appearance, located at a distance of $2.5 \mathrm{~cm}$ from the lesion and whose touch causes pain. In $30 \%$ of cases the adhesions are the painful ones, hence the need to excise the lesions while maintaining a perilesional safety zone, as well as to perform viscerolysis (65). This probably explains the persistence or recurrence of postoperative pain.

Laparotomy has rapidly lost ground in favor of less invasive laparoscopy, with fewer postoperative complications, with much faster recovery.

\section{CONCLUSIONS}

Despite decades of research, the diagnosis and treatment of endometriosis is an ongoing challenge. Elucidating the etiological factors and pathophysiological mechanisms involved in the occurrence and development of endometriotic foci, a deeper understanding of the immunological and biochemical mechanisms involved, can improve current methods of diagnosis of this complex condition. Many of the ongoing studies have had extraordinary results on in vitro cell cultures, or on animal models.

Particular emphasis is placed on cellular and biochemical markers. An ideal marker is characterized by high sensitivity and specificity, high prognostic value, the possibility of correlation between its serum levels and the severity of the disease.

Minimally invasive imaging methods are studied to compare accuracy and costs as diagnostic tests.

A wide range of factors have been studied extensively, but none of them can accurately identify the disease alone. A combination of different minimally invasive diagnostic methods is probably a promising target for the future diagnosis of endometriosis. Until then, laparoscopy followed by histopathological examination of biopsy samples from suspicious lesions remains the gold standard for the positive diagnosis of endometriosis.

\section{Conflict of interest: none declared \\ Financial support: none declared}

\section{REFERENCES}

1. Aredo JV, Heyrana KJ, Karp BI, Shah JP, Stratton P. Relating Chronic Pelvic Pain and Endometriosis to Signs of Sensitization and Myofascial Pain and Dysfunction. Semin Reprod Med. 2017 Jan;35(1):88-97.

2. Kiesel L, Sourouni M. Diagnosis of endometriosis in the 21 st century. Climacteric. 2019 Jun;22(3):296-302.

3. Czyzyk A, Podfigurna A, Szeliga A, Meczekalski B. Update on endometriosis pathogenesis. Minerva Ginecol. 2017 Oct;69(5):447-461.

4. Nisenblat V, Prentice L, Bossuyt PM, Farquhar C, Hull ML, Johnson N. Combination of the non-invasive tests for the diagnosis of endometriosis. Cochrane Database Syst Rev. 2016 Jul 13;7(7):CD012281.

5. Nisenblat $\mathrm{V}$, Bossuyt PM, Farquhar $\mathrm{C}$, Johnson N, Hull ML. Imaging modalities for the non-invasive diagnosis of endometriosis. Cochrane Database Syst Rev. 2016 Feb 26;2(2):CD009591.

6. Gupta D, Hull ML, Fraser I, Miller L, Bossuyt PM, Johnson N, Nisenblat V. Endometrial biomarkers for the non-invasive diagnosis of endometriosis. Cochrane Database Syst Rev. 2016 Apr 20;4(4):CD012165.

7. Braza-Boïls A, Marí-Alexandre J, Gilabert J, Sánchez-lzquierdo D, España F, Estellés A, Gilabert-Estellés J. MicroRNA expression profile in endometriosis: its relation to angiogenesis and fibrinolytic factors. Hum Reprod. 2014 May;29(5):978-88.

8. Marí-Alexandre J, Barceló-Molina M, Belmonte-López E, García-Oms J, Estellés
A, Braza-Boïls A, Gilabert-Estellés J. Micro-RNA profile and proteins in peritoneal fluid from women with endometriosis: their relationship with sterility. Fertil Steril. 2018 Apr;109(4):675-684.e2.

9. Agrawal S, Tapmeier T, Rahmioglu N, Kirtley $\mathrm{S}$, Zondervan K, Becker C. The miRNA Mirage: How Close Are We to Finding a Non-Invasive Diagnostic Biomarker in Endometriosis? A Systematic Review. Int J Mol Sci. 2018 Feb 17;19(2):599.

10. Hirsch M, Duffy J, Davis CJ, Nieves Plana M, Khan KS; International Collaboration to Harmonise Outcomes and Measures for Endometriosis. Diagnostic accuracy of cancer antigen 125 for endometriosis: a systematic review and meta-analysis. BJOG. 2016 Oct;123(11):1761-8.

11. Hirsch M, Duffy JMN, Deguara CS, Davis CJ, Khan KS. Diagnostic accuracy of Cancer Antigen 125 (CA125) for endometriosis in symptomatic women: A multi-center study. Eur J Obstet Gynecol Reprod Biol. 2017 Mar;210:102-107.

12. Tian Z, Chang XH, Zhao Y, Zhu HL. Current biomarkers for the detection of endometriosis. Chin Med J (Engl). 2020 Oct 5;133(19):2346-2352.

13. Nisenblat $V$, Bossuyt PM, Shaikh R, Farquhar C, Jordan V, Scheffers CS, Mol BW, Johnson N, Hull ML. Blood biomarkers for the non-invasive diagnosis of endometriosis. Cochrane Database Syst Rev. 2016 May 1;2016(5):CD012179.

14. Coutinho LM, Ferreira MC, Rocha ALL, Carneiro MM, Reis FM. New biomarkers in endometriosis. Adv Clin Chem. 2019; 89:59-77.

15. Wang P, Zhu L, Zhang X. The role of placental protein 14 in the pathogenesis of endometriosis. Reprod Sci. 2013 Dec;20(12):1465-70.

16. Wahid B, Bashir H, Bilal M, Wahid K, Sumrin A. Developing a deeper insight into reproductive biomarkers. Clin Exp Reprod Med. 2017 Dec;44(4):159-170.

17. Randall GW, Gantt PA, Poe-Zeigler RL, Bergmann CA, Noel ME, Strawbridge WR, Richardson-Cox B, Hereford JR, Reiff RH. Serum antiendometrial antibodies and diagnosis of endometriosis. Am J Reprod Immunol. 2007 Oct;58(4):374-82.

18. Bong JW, Yu CS, Lee JL, Kim CW, Yoon YS, Park IJ, Lim SB, Kim JC. Intestinal endometriosis: Diagnostic ambiguities and surgical outcomes. World J Clin Cases. 2019 Feb 26;7(4):441-451.

19. Li S, Fu X, Wu T, Yang L, Hu C, Wu R. Role of Interleukin-6 and Its Receptor in Endometriosis. Med Sci Monit. 2017 Aug 5;23:3801-3807.

20. Jiang J, Jiang Z, Xue M. Serum and peritoneal fluid levels of interleukin- 6 and interleukin-37 as biomarkers for endometriosis. Gynecol Endocrinol. 2019 Jul;35(7):571-575.

21. Hariri LP, Liebmann ER, Marion SL, Hoyer PB, Davis JR, Brewer MA, Barton JK. Simultaneous optical coherence tomography and laser induced fluorescence imaging in rat model of ovarian carcinogenesis. Cancer Biol Ther. 2010 Sep 1;10(5):438-47. 
22. Löning $M$, Diddens $H$, Friedrich $M$, Altgassen

C, Diedrich K, Hüttmann G.

Fluoreszenzdiagnostik und

photodynamische Therapie mit

5-Aminolävulinsäure induziertem

Protoporphyrin IX in der Gynäkologie: eine

Ubersicht [Fluorescence diagnosis and

photodynamic therapy with 5-aminolevulinic

acid induced protoporphyrin IX in

gynecology: an overview]. Zentralbl Gynakol. 2006 Dec;128(6):311-7.

23. Machado DE, Perini JA, Orlando MM, Santos-Oliveira R. Developing a Noninvasive Procedure Using Labeled Monoclonal Antibody Anti-VEGF (Bevacizumab) for Detection of Endometriosis. Biomed Res Int. 2015;2015:751460.

24. Coutinho LM, Ferreira MC, Rocha ALL, Carneiro MM, Reis FM. New biomarkers in endometriosis. Adv Clin Chem. 2019; 89:59-77.

25. Eyster KM, Boles AL, Brannian JD, Hansen KA. DNA microarray analysis of gene expression markers of endometriosis. Fertil Steril. 2002 Jan;77(1):38-42.

26. Mettler L, Salmassi A, Schollmeyer T, Schmutzler AG, Püngel $F$, Jonat $W$. Comparison of c-DNA microarray analysis of gene expression between eutopic endometrium and ectopic endometrium (endometriosis). J Assist Reprod Genet. 2007 Jun;24(6):249-58.

27. Eyster KM, Klinkova O, Kennedy V, Hansen KA. Whole genome deoxyribonucleic acid microarray analysis of gene expression in ectopic versus eutopic endometrium. Fertil Steril. 2007 Dec;88(6):1505-33.

28. Collins BG, Ankola A, Gola S, McGillen KL. Transvaginal US of Endometriosis: Looking Beyond the Endometrioma with a Dedicated Protocol. Radiographics. 2019 Sep-Oct; 39(5):1549-1568.

29. Guerriero S, Ajossa S, Pascual MA, Rodriguez I, Piras A, Perniciano M, Saba L, Paoletti AM, Mais V, Alcazar JL. Ultrasonographic soft markers for detection of rectosigmoid deep endometriosis. Ultrasound Obstet Gynecol. 2020 Feb; 55(2):269-273.

30. Philip CA, Dubernard G. Performances et place de l'échographie dans le diagnostic de l'endométriose, RPC Endométriose CNGOF-HAS [Performances and place of sonography in the diagnostic of endometriosis: CNGOF-HAS Endometriosis Guidelines]. Gynecol Obstet Fertil Senol. 2018 Mar;46(3):185-199. French.

31. Van Holsbeke C, Van Calster B, Guerriero S, Savelli L, Paladini D, Lissoni AA, Czekierdowski A, Fischerova D, Zhang J, Mestdagh G, Testa AC, Bourne T, Valentin L, Timmerman D. Endometriomas: their ultrasound characteristics. Ultrasound Obstet Gynecol. 2010 Jun;35(6):730-40.

32. Marret $\mathrm{H}$, Cayrol M. Échographie et doppler dans le diagnostic des tumeurs ovariennes présumées bénignes [Sonographic diagnosis of presumed benign ovarian tumors]. J Gynecol Obstet Biol Reprod (Paris). 2013 Dec;42(8):730-43. French.

33. Revzin MV, Mathur M, Dave HB, Macer ML, Spektor M. Pelvic Inflammatory Disease: Multimodality Imaging Approach with Clinical-Pathologic Correlation. Radiographics. 2016 Sep-Oct;36(5):1579-96.

34. Deslandes A, Parange N, Childs JT, Osborne B, Bezak E. Current Status of Transvaginal Ultrasound Accuracy in the Diagnosis of Deep Infiltrating Endometriosis Before Surgery: A Systematic Review of the Literature. J Ultrasound Med. 2020 Aug; 39(8):1477-1490.

35. Andres MP, Borrelli GM, Ribeiro J, Baracat EC, Abrão MS, Kho RM. Transvaginal Ultrasound for the Diagnosis of Adenomyosis: Systematic Review and Meta-Analysis. J Minim Invasive Gynecol. 2018 Feb;25(2):257-264.

36. Tellum T, Nygaard S, Lieng M. Noninvasive Diagnosis of Adenomyosis: A Structured Review and Meta-analysis of Diagnostic Accuracy in Imaging. J Minim Invasive Gynecol. 2020 Feb;27(2):408-418.e3.

37. Desplats V, Vitte RL, du Cheyron J, Roseau $G$, Fauconnier A, Moryoussef $F$. Preoperative rectosigmoid endoscopic ultrasonography predicts the need for bowel resection in endometriosis. World $\mathrm{J}$ Gastroenterol. 2019 Feb 14;25(6):696-706.

38. Thonnon C, Philip CA, Fassi-Fehri H, Bisch C, Coulon A, de Saint-Hilaire P, Dubernard $G$. Three-dimensional ultrasound in the management of bladder endometriosis. J Minim Invasive Gynecol. 2015 Mar-Apr; 22(3):403-9.

39. Coccia ME, Rizzello F, Nannini S, Cozzolino M, Capezzuoli T, Castiglione F. Ultrasoundguided excision of rectus abdominis muscle endometriosis. J Obstet Gynaecol Res. 2015 Jan;41(1):149-52.

40. Rogers PA, Adamson GD, Al-Jefout M, Becker CM, D'Hooghe TM, Dunselman GA, Fazleabas A, Giudice LC, Horne AW, Hull ML, Hummelshoj L, Missmer SA, Montgomery GW, Stratton P, Taylor RN, Rombauts L, Saunders PT, Vincent K, Zondervan KT; WES/WERF Consortium for Research Priorities in Endometriosis. Research Priorities for Endometriosis. Reprod Sci. 2017 Feb;24(2):202-226.

41. van Rijswijk J, van Welie N, Dreyer K, van Hooff MHA, de Bruin JP, Verhoeve HR, Mol F, Kleiman-Broeze KA, Traas MAF, Muijsers GJJM, Manger AP, Gianotten J, de Koning $\mathrm{CH}$, Koning AMH, Bayram N, van der Ham DP, Vrouenraets FPJM, Kalafusova M, van de Laar BIG, Kaijser J, van Oostwaard MF, Meijer WJ, Broekmans FJM, Valkenburg O, van der Voet LF, van Disseldorp J, Lambers MJ, Peters HE, Lier MCI, Lambalk CB, van Wely M, Bossuyt PMM, Stoker J, van der Veen F, Mol BWJ, Mijatovic V. The FOAM study: is Hysterosalpingo foam sonography (HyFoSy) a cost-effective alternative for hysterosalpingography (HSG) in assessing tubal patency in subfertile women? Study protocol for a randomized controlled trial. BMC Womens Health. 2018 May 9;18(1):64.

42. Coutinho A Jr, Bittencourt LK, Pires CE, Junqueira $F$, Lima CM, Coutinho E, Domingues MA, Domingues RC, Marchiori E. MR imaging in deep pelvic endometriosis: a pictorial essay. Radiographics. 2011 Mar-Apr;31(2):549-67.

43. Takeuchi M, Matsuzaki K. Adenomyosis: usual and unusual imaging manifestations, pitfalls, and problem-solving MR imaging techniques. Radiographics. 2011 Jan-Feb; 31(1):99-115.

44. Cansu A, Bulut E, Dinc G, Bekircavusoglu S, Eyuboglu I, Guven ES, Ahmetoglu A. Diagnostic Efficacy of T2 Dark Spot, T2 Dark Rim Signs, and T2 Shading on Magnetic Resonance Imaging in Differentiating Endometriomas From Hemorrhagic Cysts. J Comput Assist Tomogr. 2019 Jul/Aug; 43(4):619-622.

45. Ito TE, Abi Khalil ED, Taffel M, Moawad GN. Magnetic resonance imaging correlation to intraoperative findings of deeply infiltrative endometriosis. Fertil Steril. 2017 Feb; 107(2):e11-e12.

46. Alborzi S, Rasekhi A, Shomali Z, Madadi G, Alborzi M, Kazemi M, Hosseini Nohandani A. Diagnostic accuracy of magnetic resonance imaging, transvaginal, and transrectal ultrasonography in deep infiltrating endometriosis. Medicine (Baltimore). 2018 Feb;97(8):e9536.

47. Jarlot C, Anglade E, Paillocher N, Moreau D, Catala L, Aubé C. Caractéristiques IRM de l'endométriose profonde: corrélation aux résultats coelioscopiques [MR imaging features of deep pelvic endometriosis: correlation with laparoscopy]. J Radiol. 2008 Nov;89(11 Pt 1):1745-54. French.

48. Gauche Cazalis C, Koskas M, Martin B, Palazzo L, Madelenat P, Yazbeck C. Imagerie préopératoire dans l'endométriose profonde: échographie pelvienne, échoendoscopie rectale et IRM [Preoperative imaging of deeply infiltrating endometriosis in: Transvaginal sonography, rectal endoscopic sonography and magnetic resonance imaging]. Gynecol Obstet Fertil. 2012 Nov;40(11):634-41. French.

49. Rousset P, Gregory J, Rousset-Jablonski C, Hugon-Rodin J, Regnard JF, Chapron C, Coste J, Golfier F, Revel MP. MR diagnosis of diaphragmatic endometriosis. Eur Radiol. 2016 Nov;26(11):3968-3977.

50. Kavoussi SK, Lim CS, Skinner BD, Lebovic DI, As-Sanie S. New paradigms in the diagnosis and management of endometriosis. Curr Opin Obstet Gynecol. 2016 Aug;28(4):267-76.

51. Hirata T, Koga K, Kai K, Katabuchi H, Kitade M, Kitawaki J, Kurihara M, Takazawa N, Tanaka T, Taniguchi F, Nakajima J, Narahara H, Harada T, Horie S, Honda R, Murono K, Yoshimura K, Osuga Y. Clinical practice guidelines for the treatment of extragenital endometriosis in Japan, 2018. J Obstet Gynaecol Res. 2020 Oct 20;46(12):2474-87. 
52. Nezhat C, Falik R, McKinney S, King LP. Pathophysiology and management of urinary tract endometriosis. Nat Rev Urol. 2017 Jun;14(6):359-372.

53. Darvishzadeh A, McEachern W, Lee TK, Bhosale P, Shirkhoda A, Menias C, Lall C. Deep pelvic endometriosis: a radiologist's guide to key imaging features with clinical and histopathologic review. Abdom Radiol (NY). 2016 Dec;41(12):2380-2400.

54. Darvishzadeh A, McEachern W, Lee TK, Bhosale P, Shirkhoda A, Menias C, Lall C. Deep pelvic endometriosis: a radiologist's guide to key imaging features with clinical and histopathologic review. Abdom Radiol (NY). 2016 Dec;41(12):2380-2400.

55. Nakagawa K, Nishi Y, Sugiyama R, Kuribayashi Y, Akira S, Sugiyama R, Inoue $M$. Role of salpingoscopy in assessing the inner fallopian tubes of infertility patients with ovarian endometriomas. J Obstet Gynaecol Res. 2013 May;39(5):979-84

56. Phadnis SV, Doshi JS, Ogunnaike O, Coady A, Padwick M, Sanusi FA. Cervical endometriosis: a diagnostic and management dilemma. Arch Gynecol Obstet. 2005 Oct;272(4):289-93.
57. Milone M, Mollo A, Musella M, Maietta $\mathrm{P}$, Sosa Fernandez LM, Shatalova O, Conforti A, Barone G, De Placido G, Milone F. Role of colonoscopy in the diagnostic work-up of bowel endometriosis. World J Gastroenterol. 2015 Apr 28;21(16):4997-5001.

58. Leone Roberti Maggiore U, Ferrero S, Candiani $\mathrm{M}$, Somigliana $\mathrm{E}$, Viganò $\mathrm{P}$, Vercellini P. Bladder Endometriosis: A Systematic Review of Pathogenesis, Diagnosis, Treatment, Impact on Fertility, and Risk of Malignant Transformation. Eur Urol. 2017 May;71(5):790-807.

59. Larraín D, Buckel H, Prado J, Abedrapo M, Rojas I. Multidisciplinary laparoscopic management of deep infiltrating endometriosis from 2010 to 2017: A retrospective cohort study. Medwave. 2019 Dec 23;19(11):e7750.

60. Revised American Fertility Society classification of endometriosis: 1985. Fertil Steril. 1985 Mar;43(3):351-2.

61. Donnez J, Squifflet J, Casanas-Roux F, Pirard C, Jadoul P, Van Langendonckt A. Typical and subtle atypical presentations of endometriosis. Obstet Gynecol Clin North Am. 2003 Mar;30(1):83-93.
62. Johnson NP, Hummelshoj L, Adamson GD, Keckstein J, Taylor HS, Abrao MS, Bush D, Kiesel L, Tamimi R, Sharpe-Timms KL, Rombauts L, Giudice LC; World Endometriosis Society Sao Paulo Consortium. World Endometriosis Society consensus on the classification of endometriosis. Hum Reprod. 2017 Feb; 32(2):315-324.

63. Zhang YX, Liu XQ, Du LR, Li GZ, Lu LH, Tian HY, Gao Y, Zhang Y. Clinical analysis of transvaginal hydrolaparoscopy in infertile patients. Eur J Obstet Gynecol Reprod Biol. 2014 Nov; 182:208-10.

64. Rolla E. Endometriosis: advances and controversies in classification, pathogenesis, diagnosis, and treatment. F1000Res. 2019 Apr 23;8:F1000 Faculty Rev-529.

65. Burghaus S, Hildebrandt T, Fahlbusch C, Heusinger K, Antoniadis S, Lermann J, Hackl J, Häberle L, Renner SP, Fasching PA, Beckmann MW, Blum S. Standards Used by a Clinical and Scientific Endometriosis Center for the Diagnosis and Therapy of Patients with Endometriosis. Geburtshilfe Frauenheilkd. 2019 May; 79(5):487-497. 